\title{
Expression of MYPT1, CPI-17 and MLC20 in ileum of neonatal mouse NEC model and its significance
}

\author{
YINYU YIN ${ }^{1 *}$, YIPING LI $^{2 *}$, JIAN PAN $^{2}$, RUZE TANG $^{2}$, JIE ZHU $^{2}$, \\ ZHENFANG QIN $^{1}$, XIAOBING XU ${ }^{1}$ and JIAN WANG ${ }^{2}$ \\ ${ }^{1}$ Department of General Surgery, Xuzhou Children's Hospital, Xuzhou, Jiangsu 221006; ${ }^{2}$ Department of \\ General Surgery, Children's Hospital of Soochow University, Suzhou, Jiangsu 215025, P.R. China
}

Received March 17, 2017; Accepted July 4, 2017

DOI: $10.3892 / \mathrm{etm} .2017 .4783$

\begin{abstract}
The present study determined the changes in the expression levels of MYPT1, CPI-17 and MLC20 in the ileum of mice with neonatal induced necrotizing enterocolitis (NEC) to provide a basis for a pathogenesis model that includes smooth muscle changes during NEC. A group of 7-day-old $\mathrm{BALB} / \mathrm{c}$ mice were fed with formula (40 $\mu \mathrm{l} / \mathrm{g}, 5$ times/day) and given hypoxia treatments $\left(5 \% \mathrm{O}_{2}\right.$ and $95 \% \mathrm{~N}_{2}$ for $10 \mathrm{~min}$, twice daily) for 4 days to induce NEC and establish a mouse model. A control group of 7-day-old BALB/c mice were left with their mother for the duration of the treatment. After establishing the model, the two groups of mice were sacrificed, and the terminal ileum tissue was collected and subjected to western blot analysis and immunohistochemistry. The results showed the expression levels of MYPT1 and pMYPT1 in the ileum of the mice in the NEC group were lower than those in the control group $(\mathrm{P}<0.01)$. The levels of CPI17 and pCPI17 were higher in the NEC group compared with those in the control group. The expression level of MLC20 in NEC group was lower than that in the control group $(\mathrm{P}<0.01)$, but the level of pMLC20 in the NEC group was higher $(\mathrm{P}<0.05)$. The results of immunohistochemistry showed that the staining intensities of MYPT1, CPI-17 and MLC20 in the NEC group were lighter than those in the control group, and the proportion of positive cells was also lower in the NEC group $(\mathrm{P}<0.01)$. Taken together our results suggest that establishment of NEC is accompanied by changes in the protein levels of MYPT1 and pCPI-17, which can regulate smooth muscle contraction in the ileum.
\end{abstract}

Correspondence to: Dr Jian Wang, Department of General Surgery, Children's Hospital of Soochow University, 92 Zhongnan Street, Suzhou, Jiangsu 215025, P.R. China

E-mail: yi55hj@163.com

*Contributed equally

Key words: necrotizing enterocolitis, MYPT1, CPI17, MLC20, mouse model

\section{Introduction}

Necrotizing enterocolitis (NEC) is the most common life-threatening acute gastrointestinal disease of the neonatal period. NEC is caused by intestinal mucosal damage that can occur due to different reasons (1). Mucosal damage has been associated with formula feeding, ischemia, hypoxia, intestinal bacterial translocation and other factors that lead to systemic or local necrosis in the small intestine and colon (1). With the improvement of neonatal intensive care in recent years and the continuous increased survival rates of premature children with low birth weight, the incidence of NEC has also been maintained at a high level. It has been reported that NEC accounts for $1-5 \%$ of all the children in neonatal intensive care units (NICUs) $(2,3)$. The incidence of NEC in infants with extremely low birth weight can be as high as $5-10 \%$, which is higher than the incidence for most gastrointestinal malformations (4). NEC is the leading cause of death in the NICU (5).

Studies on the causes of NEC have mainly focused on immune system dysfunction leading to intestinal inflammation and increased susceptibility to pathogens $(6,7)$. Many studies have focused on bacterial and metabolic-mediated inflammatory responses affecting intestinal epithelial cells $(8,9)$. For example, the increased expression of Toll Like Receptor 4 (TLR4) in those cells can inhibit intestinal epithelium cell migration, leading to a disorder of mucosal repair, and inducing intestinal epithelial stem cell apoptosis and autophagy (10-12). However, other factors that may clearly play a role in the pathogenesis of NEC have not been studied as much.

The level of phosphorylation of the myosin light chain 20 (MLC20) protein determines the intensity of contraction of smooth muscle in the small intestine. The ratio of myosin light chain kinase/myosin light chain phosphatase (MLCK/MLCP) directly affects the phosphorylation of MLC20 and maintains the dynamic balance between MLC20 and the phosphorylated MLC20 (13).

There are two main regulators for the catalytic activity of MLCP, namely the protein kinase C-potentiated phosphatase inhibitor of $17 \mathrm{ku}$ (CPI-17) and the myosin phosphatase target subunit 1 (MYPT1) (14,15). CPI-17, which is expressed in the trachea, uterus, blood vessels and throughout the gastrointestinal tract, is a specific inhibitor of MLCP that 
depends on phosphorylation for regulating smooth muscle contraction (16). Rho-kinase (17), protein kinase N (PKN) (18) and protein kinase C (PKC) (19) can all directly act on CPI-17 to phosphorylate threonine on position 38 , causing inhibitory effects when interacting with MLCP (20). Phosphorylated CPI-17 competitively inhibits the dephosphorylation of MLC20 by MLCP. Phosphorylated CPI-17 can bind to the catalytic subunit protein phosphatase 1 catalytic subunit (PP1c) of MLCP to improve the phosphorylation of intracellular MLC20, which enhances smooth muscle contraction. When the kinase signal is terminated, phosphorylated CPI-17 is dephosphorylated by protein phosphatase $2 \mathrm{~A}$ or protein phosphatase $2 \mathrm{C}$, resulting in a change in the ratio of phosphorylated CPI-17/dephosphorylated CPI-17, thereby regulating MLCP activity (15).

MYPT1, PP1c and an unidentified subunit (M20) form the MLCP holoenzyme (18). The main role of MYPT1 is to inhibit the activity of MLCP (21). It does so by enhancing the catalytic activity of PP1c (22), phosphorylating its subunits Ser-694 (22), Thr696 and Thr850 (23-25), and changing the conformation of PP1c to enhance binding to phosphorylated CPI-17. Since intestinal smooth muscle spasm followed by ischemia and hypoxia occurs prior to the occurrence of intestinal necrosis during the development of NEC, it is likely that disease progression is accompanied by changes in the expression of the abovementioned proteins. The aim of the present study was to detect those changes using a mouse model of NEC.

\section{Materials and methods}

NEC model. Seven-day-old SPF grade BALB/c mice [license no. SCXK (Su) 2013-003; Joinn Laboratories, Suzhou, China] were used to establish the NEC model according to published methods $(26,27)$ that can mimic NEC in humans. The newborn mice $(n=25)$ were separated from their mother, and were subjected to formula feeding (40 $\mu \mathrm{l} / \mathrm{g}, 5$ times/day) with Nestlé infant formula and Petag Esbilac milk powder for newborn puppy $(2: 1)$ through oral intubation with a $24 \mathrm{G}$ Y-type closed venous indwelling catheter (BD Biosciences, San Diego, CA, USA). The feeding lasted about $2 \mathrm{~min}$ for each mouse. The mice were intermittently placed in the hypoxic chamber (Billups-Rothenberg, Del Mar, CA, USA), with an oxygen concentration at $5 \%$ controlled by an oxygen concentration MT-01 monitor (Nanjing Mingtong Medical Treatment Instruments, Co., Ltd., Nanjing, China), for periods of $10 \mathrm{~min}$, twice a day. The treatment was repeated each day for 4 days. The mice were sacrificed $6 \mathrm{~h}$ after the last treatment. Ileum $(1 \mathrm{~cm})$ was collected at $0.5 \mathrm{~cm}$ from the ileocecus and was immersed in formalin for pathological and immunohistochemical tests. In addition, $2 \mathrm{~cm}$ of the ileum was taken from the proximal end and placed into EP tubes for storage at $-80^{\circ} \mathrm{C}$ to perform western blot analysis.

For the control group, 25 newborn mice were allowed to feed normally from their mother for 4 days, and were then sacrificed by cervical dislocation and ileum samples were treated as for the NEC model mice.

$H \& E$ staining and pathological scoring. The distal end of the ileum was fixed, dehydrated, embedded in paraffin and cut into $5 \mu \mathrm{m}$ slices. After hematoxylin and eosin (H\&E) staining, the pathological changes of all the sections were observed by optical microscope (BX-42; Olympus, Tokyo, Japan). Two independent pathologists performed double-blind scoring according to published standards (28). The scores of the most severe pathological lesions in the samples were used to determine the degree of intestinal injury. A score of $\geq 2$ points was considered indicative of NEC.

Western blot analysis. The protein levels of MYPT1, CPI-17, and MLC20 in the ileum tissues of the control group and in the tissues with a pathological score $\geq 2$ in the NEC group $(n=12)$ were measured by standard western blot analysis. Briefly, the total protein was extracted from each sample in a lysis buffer. The protein concentration was measured by the BCA method (Beyotime Institute of Biotechnology, Shanghai, China). Next, $20 \mu \mathrm{g}$ protein from each sample were subjected to SDS-PAGE electrophoresis (stacker at $60 \mathrm{~mA}, 10 \%$ separation gel at $100 \mathrm{~mA}$ ). The samples were then transferred to a PVDF membrane, using the wet method (280 mA for $1.5 \mathrm{~h}$ ). The membrane was blocked with 5\% BSA at room temperature and primary antibodies including rabbit polyclonal MYPT1 antibody (dilution, 1:1,000; cat. no. ab59235), rabbit polyclonal phospho MYPT1 antibody (dilution, 1:1,000; cat. no. ab59202), rabbit monoclonal CPI17 $\alpha$ antibody (dilution, 1:1,000; cat. no. ab32213), rabbit monoclonal phospho-CPI17 $\alpha$ antibody (dilution, 1:1,000; cat. no. ab52174), rabbit monoclonal MYL12B (dilution, 1:1,000; cat. no. ab137063), rabbit monoclonal phospho-MYL12B (dilution, 1:1,000; cat. no. ab177354) and rabbit polyclonal $\beta$-actin antibody (dilution, 1:5,000; cat. no. ab8227), purchased from Abcam (Cambridge, MA, USA) were added and incubated overnight at $4^{\circ} \mathrm{C}$. After washing, secondary goat anti-rabbit (HRP) IgG antibody (dilution, 1:2,000; cat. no. ab6721) were added and incubated for $1 \mathrm{~h}$. ECL luminous agent (Applygen Technologies, Inc., Beijing, China) was added and GE gel imager (LAS4010) was used to detect the signal and record the results.

Immunohistochemistry. The slices were first baked in an incubator at $70^{\circ} \mathrm{C}$ for $30 \mathrm{~min}$ before dewaxing. and rehydrating them. Then the slides were soaked twice for $5 \mathrm{~min}$ in xylene, followed by washing twice with $100 \%$ ethanol ( 2 min each time), and washing twice with $95 \%$ ethanol ( 2 min each time). Trypsin was used to retrieve antigens and SP staining was performed. The primary antibodies including anti-CPI17 $\alpha$ (1:100; Abcam), anti-MYPT1 (1:100; Abcam) and anti-MYL12B (1:200; Abcam) antibodies were added and the samples were incubated overnight at $4^{\circ} \mathrm{C}$. After washing the next day, secondary antibody (p6261; Abcam) was added and color development was performed (DAB chromogen for $1 \mathrm{ml}$ substrate). An Olympus inverted fluorescence microscope (IX73) was used to capture images.

Three independent pathologists observed the slices, selecting five representative visual fields (10x40 times) from each slide. A scoring system gave 1 point to samples that constituted the number of cytoplasmic-positive cells accounting for $<25 \%$ of the total number of cells (weak positive \pm ), 2 points when the percentage of positive cells was between 25 and $50 \%$ $(+), 3$ points for a $50-75 \%$ positivity rate $(++)$, and 4 points for positivities $>75 \%(+++)$. Additionally, the intensity of the color was represented by $( \pm),(+)$ and $(++)$ corresponding to 1,2 and 
A

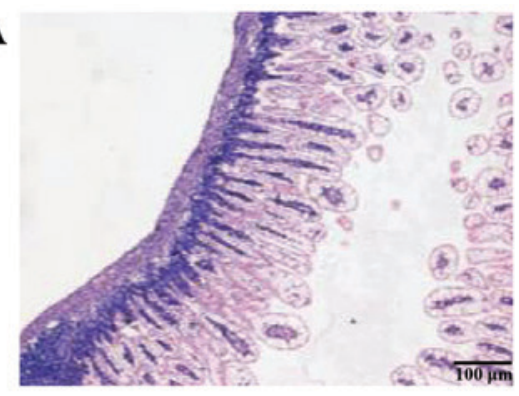

C

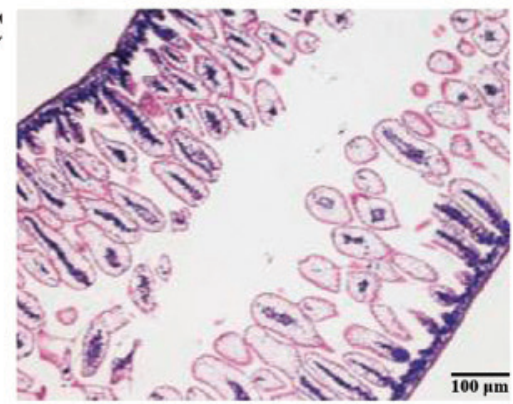

E

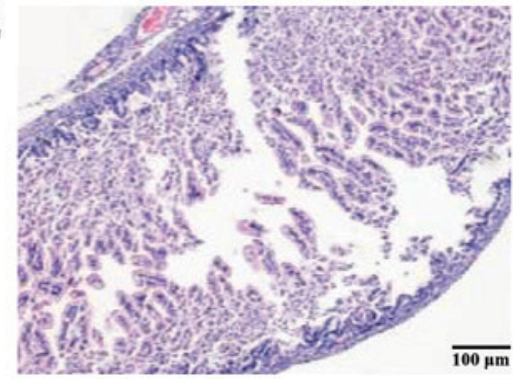

B

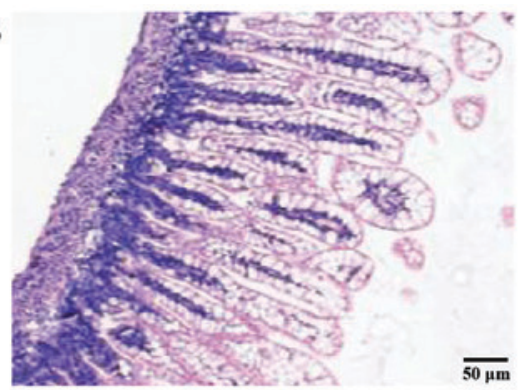

D

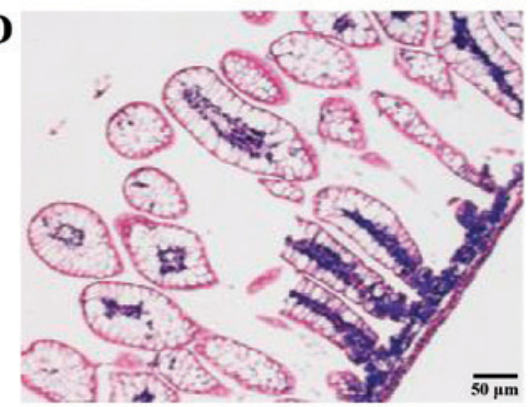

F

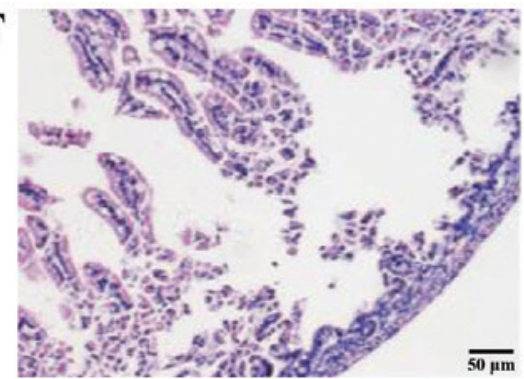

H

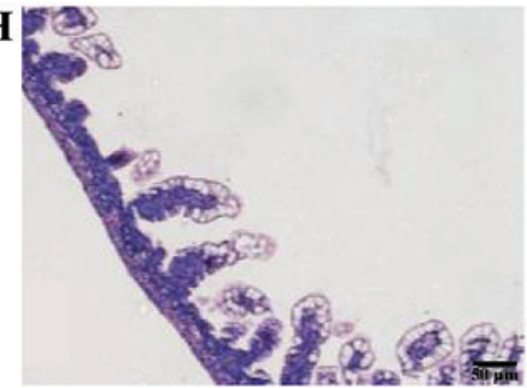

Figure 1. H\&E staining of mouse terminal ileum. (A and B) Control group, intestinal villi and epithelium were intact, tissue structure was normal, scored '0' points. (C-F) NEC group, moderate to severe submucosal separation and/or lamina propria separation combined with local villi shedding, scored '2-3' points. ( $\mathrm{G}$ and $\mathrm{H}$ ) NEC group, the intestinal villi disappeared, intestinal necrosis, scored '4' points. NEC, necrotizing enterocolitis.

3 points. The scores from the two methods were multiplied to get the final score.

Statistical analysis. The SPSS 20.0 statistical software (IBM SPSS, Armonk, NY, USA) was used for analyses. Mean values were expressed as mean \pm standard deviation. Comparisons were performed by $\mathrm{t}$ or $\chi^{2}$ tests. $\mathrm{P}<0.05$ was considered to indicate a statistically significant difference.

\section{Results}

$H \& E$ staining. H\&E staining was observed under a light microscope. The intestinal villi of samples from mice in the control group were intact and the submucosal layer had no edema. In the NEC group, the structure of the intestinal wall was damaged and the villi appeared to be broken (Fig. 1).
Western blot analysis. The expression levels of MYPT1 and pMYPT1 in the ileum of mice of the NEC group were lower than those of the control group $(\mathrm{P}<0.01)$. Levels of CPI17 in the NEC group were lower than those in control group. But the levels of pCPI17 in the NEC group were found to be higher when compared with those in the control group. However, the expression levels of M1720 in the NEC group were lower than those in the control group $(\mathrm{P}<0.01)$. The expression levels of pMLC20 in the NEC group were higher than those in the control group $(\mathrm{P}<0.05)$ (Fig. 2).

Immunohistochemistry. The expression levels of CPI-17, MYPT1 and MLC20 in the ileum of the NEC group mice and the control group mice were mainly expressed in the cytoplasm, but the staining intensities for CPI-17, MYPT1 and MLC20 were lighter in the NEC group mice. In addition, 
A
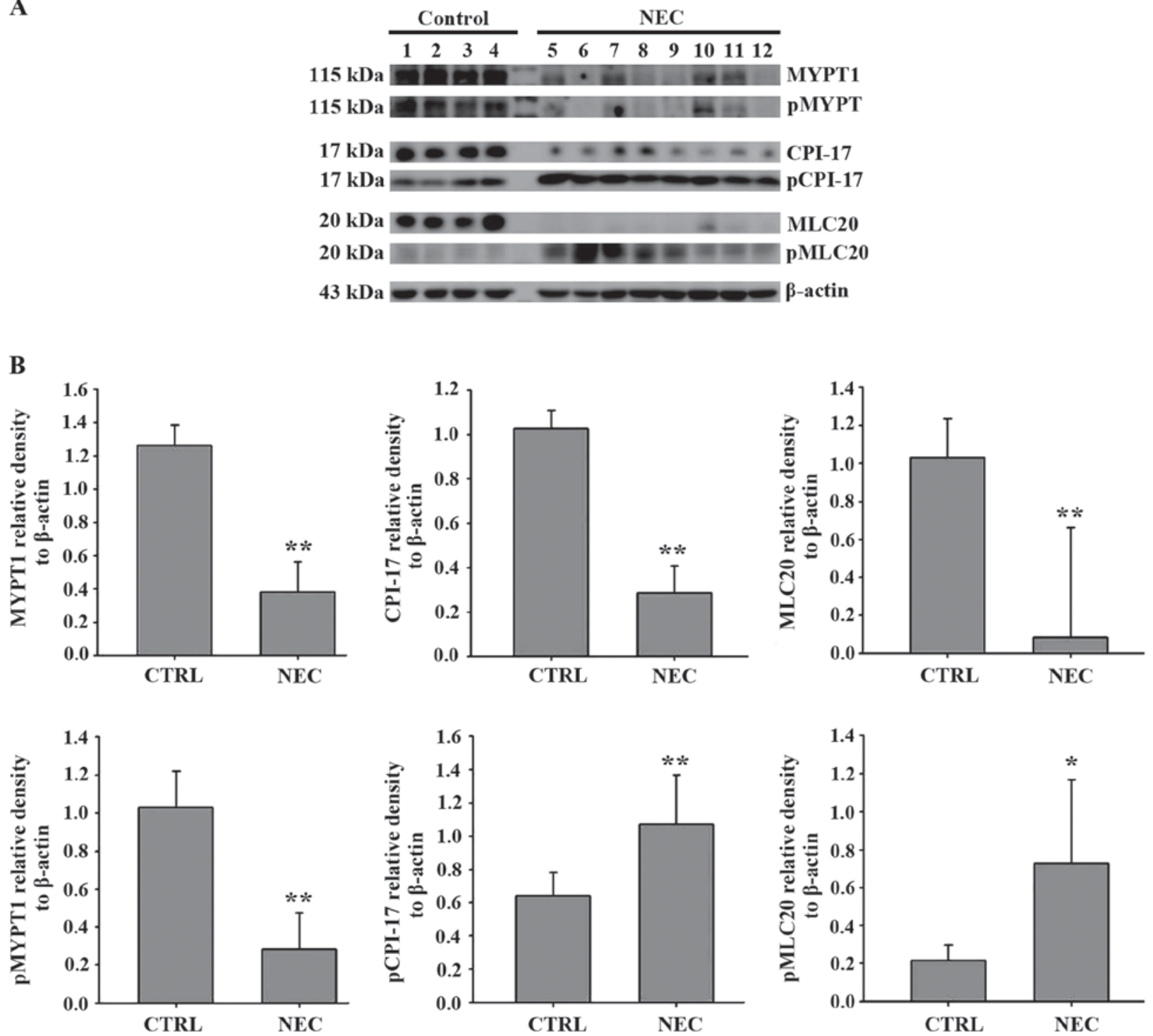

Figure 2. Expression of MYPT1, CPI17 and MLC20 in terminal ileum of mice in the NEC and control groups detected by western blot analysis. (A) Protein expression detected by western blot analysis. (B) Relative protein expression levels ( ${ }^{* *} \mathrm{P}<0.01$; ${ }^{*} \mathrm{P}<0.05$ ). NEC, necrotizing enterocolitis.

Table I. Scoring of the immunohistochemical results of both NEC and control groups.

\begin{tabular}{lccc}
\hline & \multicolumn{3}{c}{$\begin{array}{c}\text { Scoring of the immunohistochemical } \\
\text { results (mean } \pm \text { SD) }\end{array}$} \\
\cline { 2 - 4 } Variables & CPI-17 & MYPT1 & MLC20 \\
\hline Control group & $7.47 \pm 3.23$ & $9.13 \pm 3.16$ & $10.21 \pm 3.14$ \\
NEC group & $1.80 \pm 0.77$ & $4.53 \pm 1.77$ & $1.33 \pm 0.49$ \\
T-value & 6.614 & 4.921 & 10.458 \\
P-value & $<0.001$ & $<0.001$ & $<0.001$ \\
\hline
\end{tabular}

SD, standard deviation; NEC, necrotizing enterocolitis.

the proportion of positive cells in the NEC group was lower than that in the control group (Fig. 3). Statistically significant differences were found between the scores from mice in the two groups (Table I).

\section{Discussion}

At present, the pathogenic mechanisms of NEC remain to be determined. Known risk factors for the disease include premature delivery, enteral feeding, bacterial infections, persistent intestinal ischemia and the use of certain drugs (29-34). In recent years, an altered intestinal structure and immature immune function have also been found to be conducive to $\operatorname{NEC}(35,36)$. A reflex triggered by hypoxic damage can cause the mesenteric blood vessels and intestinal smooth muscles to spasm, resulting in significant reduction in intestinal blood flow. In addition, improper feeding, such as feeding with high-tension formulas, can also reduce the intestinal blood flow, which in turn leads to intestinal ischemic damage. Intestinal ischemic damage alters the normal mucus production, which can increase susceptibility of the intestinal tract to bacterial invasion (37). On the other hand, feeding provides sufficient substrate for intestinal bacteria to outgrow. Bacteria can penetrate the intestinal wall, resulting in the production and accumulation of hydrogen that shows up as gas accumulation on the intestinal wall in X-ray 

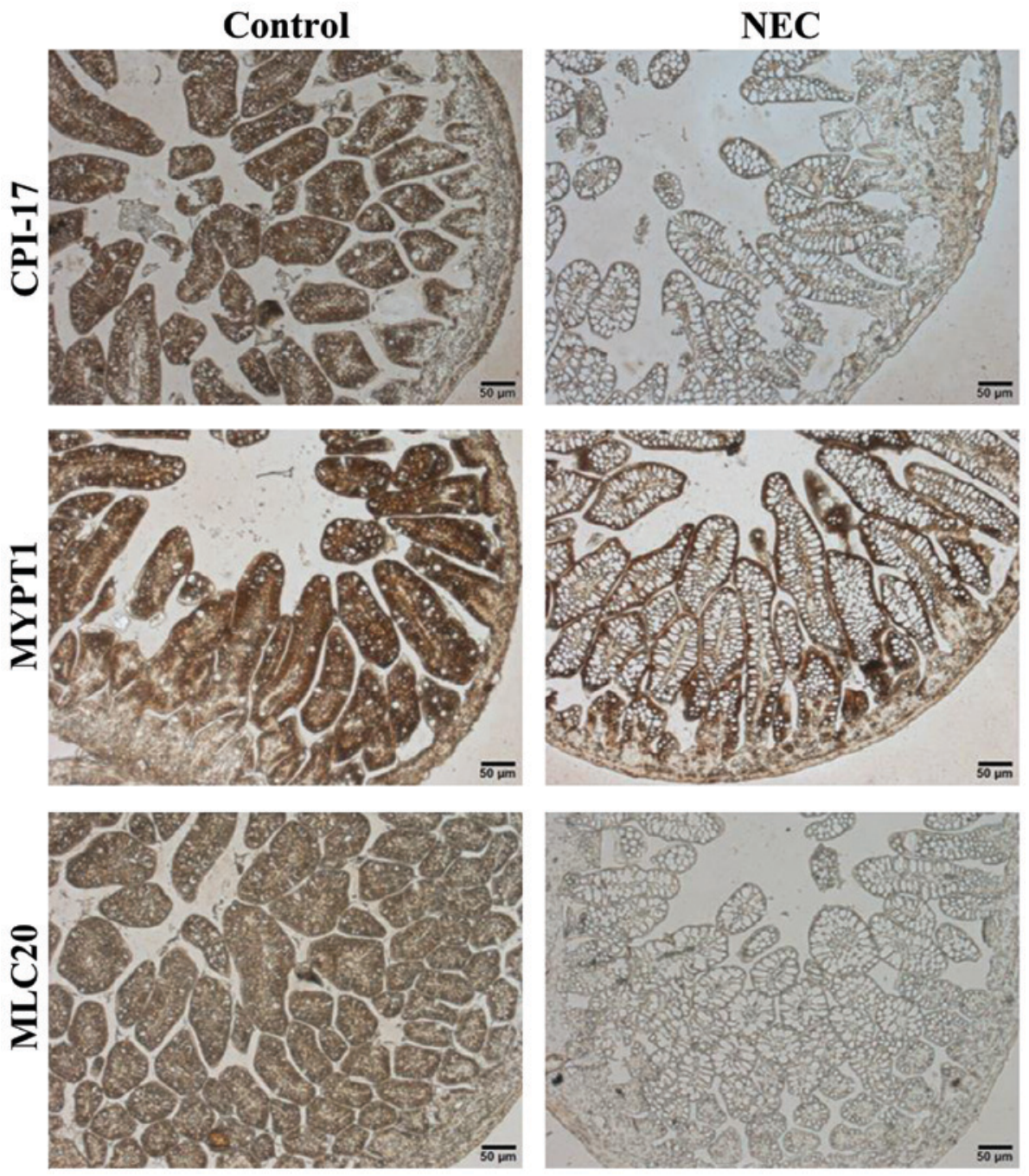

Figure 3. Immunohistochemistry images of the expression of CPI-17, MYPT1 and MLC20 in the terminal ileum of mice. The staining of CPI-17, MYPT1 and MLC20 in the ileum of the NEC group was lighter than that of the control group. Statistically significant differences were found in scores between the two groups $(\mathrm{P}<0.01)$. NEC, necrotizing enterocolitis.

films. Eventually, the gas can enter the portal vein and this can be detected by X-ray or liver B ultrasound (38). Intestinal necrosis starts from the inner most mucosal layer, gradually spanning the whole thickness of the intestinal wall, leading to perforation. If allowed to progress, the disease leads to necrosis of the whole layer of intestinal wall, perforation, peritonitis, sepsis and death. It is clear then that intestinal necrosis in NEC is preceded by changes in the state of intestinal contraction and understanding these changes is key to clarifying the pathogenic mechanisms. In the present study, altered expression of proteins related to the intestinal tube contraction were detected in the mouse ileum of NEC model mice, and it is possible that these changes may have triggered or exacerbated hypoxia-ischemia in the intestinal tissues.

The changes in the phosphorylation level of MLC20 due to detected changes in the MLCK/MLCP ratio and induced by CPI-17, would lead to smooth muscle contraction. The non-phosphorylated CPI-17 forms a unique ' $\mathrm{V}$ ' shape structure, with the position-38 threonine located in the middle of the subunit. The phosphorylation of threonine on position $38 \mathrm{can}$ be induced by ROCK and other upstream factors, resulting in changes of the spatial conformation of CPI-17. Phosphorylated residues on the surface of the protein can increase the inhibitory effects of CPI-17 on MLCP by 1,000 times (39). In the present study, the expression of pCPI-17 in the ileum of the NEC model mice was higher than that in the control group $(\mathrm{P}<0.01)$, and thereby the dephosphorylation of MLC20 was inhibited, giving rise to high levels of phosphorylated MLC20 $(\mathrm{P}<0.01)$. Under such conditions, cross-linking between actin and myosin would have been increased, causing actin microfilament contraction, and intestinal spasm, leading to mucosal ischemia and hypoxia, and ultimately promoting the development of intestinal necrosis.

MYPT1 is a regulatory subunit of MLCP, MLCP has different substrates in different tissues, dephosphorylation by the enzyme's catalytic action results in different biological effects (40-42). MLCP is an important substrate in the Rho/ROCK pathway, and the activated ROCK can phosphorylate the MYPT1 subunit, which renders the whole MLCP inactive and unable to catalyze the dephosphorylation of phosphorylated myosin light chain (pMLC20). The resulting increased levels of pMLC20 lead to the cross-linking of actin and myosin proteins, leaving the smooth muscle in a spastic state (43). Notably, results of this study showed 
that the expression of MYPT1 in the NEC group was lower than that in the control group $(\mathrm{P}<0.05)$, which may have led to decreased catalytic effects of MLCP on pMLC20 dephosphorylation. With the involvement of phosphorylated CPI-17, the phosphorylation levels of MLC20 would have been kept at high levels, leading to sustained intestinal smooth muscle contraction, that would eventually lead to intestinal necrosis due to ischemia and hypoxia.

Nevertheless, the intestinal ischemia and hypoxia caused by persistent intestinal contraction is only one of the conditions that promote intestinal necrosis. Intermittent hypoxia can also lead to the contraction of mesenteric blood vessels $(44,45)$, and increase the ischemic state of the intestinal wall tissue. In addition, the relationship between abnormal intestinal smooth muscle contraction and changes in the expression of other known risk factors such as TLR4 and TLR9 as well as epithelial cell apoptosis needs to be further studied. Our study has provided new ideas for clarifying the pathogenesis of NEC, an essential element for improving the prevention and treatment of this disease.

\section{References}

1. Jilling T, Lu J, Jackson M and Caplan MS: Intestinal epithelial apoptosis initiates gross bowel necrosis in an experimental rat model of neonatal necrotizing enterocolitis. Pediatr Res 55: 622-629, 2004

2. Eltayeb AA, Mostafa MM, Ibrahim NH and Eltayeb AA: The role of surgery in management of necrotizing enterocolitis. Int J Surg 8: 458-461, 2010.

3. Meinzen-Derr J, Morrow AL, Hornung RW, Donovan EF, Dietrich KN and Succop PA: Epidemiology of necrotizing enterocolitis temporal clustering in two neonatology practices. J Pediatr 154: 656-661, 2009.

4. Thompson AM and Bizzarro MJ: Necrotizing enterocolitis in newborns: Pathogenesis, prevention and management. Drugs 68: 1227-1238, 2008.

5. Fitzgibbons SC, Ching Y, Yu D, Carpenter J, Kenny M, Weldon C, Lillehei C, Valim C, Horbar JD and Jaksic T: Mortality of necrotizing enterocolitis expressed by birth weight categories. J Pediatr Surg 44: 1072-1075, discussion 1075-1076, 2009.

6. Caplan MS: Neonatal necrotizing enterocolitis. Introduction. Semin Perinatol 32: 69, 2008.

7. Lin JY, Egan CE, Sodhi C, Landreneau J, Good M, Jia H, Afrazi A, Branca M, Ma C, Prindle T, et al: Toll Like Receptor 4 (TLR4) Regulates the Recruitment of CD4 T Cells in the Newborn Intestine in the Pathogenesis of Necrotizing Enterocolitis. J Surg Res 179: 319-320, 2013.

8. Cetin S, Ford HR, Sysko LR, Agarwal C, Wang J, Neal MD, Baty C, Apodaca G and Hackam DJ: Endotoxin inhibits intestinal epithelial restitution through activation of Rho-GTPase and increased focal adhesions. J Biol Chem 279: 24592-24600, 2004.

9. Qureshi FG, Leaphart C, Cetin S, Li J, Grishin A, Watkins S, Ford HR and Hackam DJ: Increased expression and function of integrins in enterocytes by endotoxin impairs epithelial restitution. Gastroenterology 128: 1012-1022, 2005.

10. Yu Y, Shiou SR, Guo Y, Lu L, Westerhoff M, Sun J, Petrof EO and Claud EC: Erythropoietin protects epithelial cells from excessive autophagy and apoptosis in experimental neonatal necrotizing enterocolitis. PLoS One 8: e69620, 2013.

11. Hackam DJ, Good M and Sodhi CP: Mechanisms of gut barrier failure in the pathogenesis of necrotizing enterocolitis: Toll-like receptors throw the switch. Semin Pediatr Surg 22: 76-82, 2013.

12. Leaphart CL, Jaime C, Gribar SC, Cetin S, Li J, Branca MF, Dubowski TD, Sodhi CP and Hackam DJ: A critical role for TLR4 in the pathogenesis of necrotizing enterocolitis by modulating intestinal injury and repair. J Immunol 179: 4808-4820, 2007.

13. Feighery LM, Cochrane SW, Quinn T, Baird AW, O'Toole D, Owens SE, O'Donoghue D, Mrsny RJ and Brayden DJ: Myosin light chain kinase inhibition: correction of increased intestinal epithelial permeability in vitro. Pharm Res 25: 1377-1386, 2008.
14. Mori D, Hori M, Murata T, Ohama T, Kishi H, Kobayashi S and Ozaki H: Synchronous phosphorylation of CPI-17 and MYPT1 is essential for inducing $\mathrm{Ca}^{2+}$ sensitization in intestinal smooth muscle. Neurogastroenterol Motil 23: 1111-1122, 2011.

15. Takizawa N, Niiro N and Ikebe M: Dephosphorylation of the two regulatory components of myosin phosphatase, MBS and CPI17. FEBS Lett 515: 127-132, 2002.

16. Kitazawa T: $\mathrm{G}$ protein-mediated $\mathrm{Ca}^{2+}$-sensitization of $\mathrm{CPI}-17$ phosphorylation in arterial smooth muscle. Biochem Biophys Res Commun 401: 75-78, 2010.

17. Koyama M, Ito M, Feng J, Seko T, Shiraki K, Takase K, Hartshorne DJ and Nakano T: Phosphorylation of CPI-17, an inhibitory phosphoprotein of smooth muscle myosin phosphatase, by Rho-kinase. FEBS Lett 475: 197-200, 2000.

18. Hamaguchi T, Ito M, Feng J, Seko T, Koyama M, Machida H, Takase K, Amano M, Kaibuchi K, Hartshorne DJ, et al: Phosphorylation of CPI-17, an inhibitor of myosin phosphatase, by protein kinase N. Biochem Biophys Res Commun 274: 825-830, 2000.

19. Walsh MP, Susnjar M, Deng J, Sutherland C, Kiss E and Wilson DP: Phosphorylation of the protein phosphatase type 1 inhibitor protein CPI-17 by protein kinase C. Methods Mol Biol 365: 209-223, 2007.

20. Niiro N, Koga Y and Ikebe M: Agonist-induced changes in the phosphorylation of the myosin- binding subunit of myosin light chain phosphatase and CPI17, two regulatory factors of myosin light chain phosphatase, in smooth muscle. Biochem J 369: $117-128,2003$.

21. Eto M, Kitazawa T and Brautigan DL: Phosphoprotein inhibitor CPI-17 specificity depends on allosteric regulation of protein phosphatase-1 by regulatory subunits. Proc Natl Acad Sci USA 101: 8888-8893, 2004.

22. Pinheiro AS, Marsh JA, Forman-Kay JD and Peti W: Structural signature of the MYPT1-PP1 interaction. J Am Chem Soc 133: 73-80, 2011.

23. Yuen S, Ogut O and Brozovich FV: MYPT1 protein isoforms are differentially phosphorylated by protein kinase G. J Biol Chem 286: 37274-37279, 2011.

24. Murányi A, Derkach D, Erdodi F, Kiss A, Ito M and Hartshorne DJ: Phosphorylation of Thr695 and Thr850 on the myosin phosphatase target subunit: Inhibitory effects and occurrence in A7r5 cells. FEBS Lett 579: 6611-6615, 2005.

25. Birukova AA, Smurova K, Birukov KG, Kaibuchi K, Garcia JG and Verin AD: Role of Rho GTPases in thrombin-induced lung vascular endothelial cells barrier dysfunction. Microvasc Res 67: 64-77, 2004.

26. Gribar SC, Sodhi CP, Richardson WM, Anand RJ, Gittes GK, Branca MF, Jakub A, Shi XH, Shah S, Ozolek JA, et al: Reciprocal expression and signaling of TLR4 and TLR9 in the pathogenesis and treatment of necrotizing enterocolitis. J Immunol 182: 636-646, 2009

27. Neal MD, Sodhi CP, Dyer M, Craig BT, Good M, Jia H, Yazji I, Afrazi A, Richardson WM, Beer-Stolz D, et al: A critical role for TLR4 induction of autophagy in the regulation of enterocyte migration and the pathogenesis of necrotizing enterocolitis. J Immunol 190: 3541-3551, 2013.

28. Ran-Ressler RR,Khailova L, Arganbright KM,Adkins-Rieck CK, Jouni ZE, Koren O, Ley RE, Brenna JT and Dvorak B: Branched chain fatty acids reduce the incidence of necrotizing enterocolitis and alter gastrointestinal microbial ecology in a neonatal rat model. PLoS One 6: e29032, 2011.

29. Yu P, Bu H, Wang H, Zhao G, Zhang J and Zhou Q: Comparative study on image analysis and manual counting of immunohistochemistry. Sheng Wu Yi Xue Gong Cheng Xue Za Zhi 20: 288-290, 2003 (In Chinese).

30. Choi YY: Necrotizing enterocolitis in newborns: Update in pathophysiology and newly emerging therapeutic strategies. Korean J Pediatr 57: 505-513, 2014.

31. Tanner SM, Berryhill TF, Ellenburg JL, Jilling T, Cleveland DS, Lorenz RG and Martin CA: Pathogenesis of necrotizing enterocolitis: Modeling the innate immune response. Am J Pathol 185: 4-16, 2015.

32. Elgin TG, Kern SL and McElroy SJ: Development of the neonatal intestinal microbiome and its association with necrotizing enterocolitis. Clin Ther 38: 706-715, 2016.

33. Neu $\mathrm{J}$ and Walker WA: Necrotizing enterocolitis. N Engl J Med 364: 255-264, 2011.

34. Figueras-Aloy J, Rodríguez-Miguélez JM, Iriondo-Sanz M, Salvia-Roiges MD, Botet-Mussons F and Carbonell-Estrany X: Intravenous immunoglobulin and necrotizing enterocolitis in newborns with hemolytic disease. Pediatrics 125: 139-144, 2010. 
35. Lee JH: An update on necrotizing enterocolitis: Pathogenesis and preventive strategies. Korean J Pediatr 54: 368-372, 2011.

36. Lee JS and Polin RA: Treatment and prevention of necrotizing enterocolitis. Semin Neonatol 8: 449-459, 2003.

37. Lim JC, Golden JM and Ford HR: Pathogenesis of neonatal necrotizing enterocolitis. Pediatr Surg Int 31: 509-518, 2015.

38. Abboud B, El Hachem J, Yazbeck T and Doumit C: Hepatic portal venous gas: Physiopathology, etiology, prognosis and treatment. World J Gastroenterol 15: 3585-3590, 2009.

39. Ohki S, Eto M, Shimizu M, Takada R, Brautigan DL and Kainosho M: Distinctive solution conformation of phosphatase inhibitor CPI-17 substituted with aspartate at the phosphorylation-site threonine residue. J Mol Biol 326: 1539-1547, 2003.

40. Joo EE and Yamada KM: MYPT1 regulates contractility and microtubule acetylation to modulate integrin adhesions and matrix assembly. Nat Commun 5: 3510, 2014.

41. Lubomirov LT, Schubert R, Gagov HS, Duridanova DB and Pfitzer G: Urocortin decreases phosphorylation of MYPT1 and increases the myosin phosphatase activity via elevation of the intracellular level of cAMP. Biofizika 51: 773-780, 2006 (In Russian).
42. Huang H, Ruan H, Aw MY, Hussain A, Guo L, Gao C, Qian F, Leung T, Song H, Kimelman D, et al: Mypt1-mediated spatial positioning of Bmp2-producing cells is essential for liver organogenesis. Development 135: 3209-3218, 2008.

43. Patel CA and Rattan S: Spontaneously tonic smooth muscle has characteristically higher levels of RhoA/ROK compared with the phasic smooth muscle. Am J Physiol Gastrointest Liver Physiol 291: G830-G837, 2006.

44. Osmond JM, Gonzalez Bosc LV, Walker BR and Kanagy NL: Endothelin-1-induced vasoconstriction does not require intracellular $\mathrm{Ca}^{2+}$ waves in arteries from rats exposed to intermittent hypoxia. Am J Physiol Heart Circ Physiol 306: H667-H673, 2014.

45. Webster BR, Osmond JM, Paredes DA, DeLeon XA, JacksonWeaver O, Walker BR and Kanagy NL: Phosphoinositidedependent kinase-1 and protein kinase $\mathrm{C} \delta$ contribute to endothelin-1 constriction and elevated blood pressure in intermittent hypoxia. J Pharmacol Exp Ther 344: 68-76, 2013. 